\title{
Mechanical behavior of PVD coatings deposited on ADI
}

Diego Alejandro Colombo ${ }^{1}$, Adriana Beatriz Márquez ${ }^{2}$, Fernando García Marro ${ }^{3}$, Luis Miguel Llanes ${ }^{3}$, Amadeo Daniel Sosa ${ }^{1}$

\footnotetext{
${ }^{1}$ Instituto de Investigaciones en Ciencia y Tecnología de Materiales, Universidad Nacional de Mar del Plata, CONICET, Facultad de Ingeniería, Av. J .B. Justo 4302, B7608FDQ, Mar del Plata, Buenos Aires, Argentina.

${ }^{2}$ Instituto de Física del Plasma, Universidad de Buenos Aires, CONICET, Facultad de Ciencias Exactas y Naturales, Intendente Güiraldes 2160 Pabellón I PB Ciudad Universitaria, C1428EGA, Cuidad Autónoma de Buenos Aires, Argentina.

${ }^{3}$ Departamento de Ciencia de los Materiales y Ingeniería Metalúrgica, Universitat Politécnica de Catalunya, Av. Diagonal 647, 08028, Barcelona, Cataluña, España.

e-mail: diegocolombo@fi.mdp.edu.ar,mechever@fi.mdp.edu.ar, adsosa@fi.mdp.edu.ar, amarquez@df.uba.ar; fernando.garcia.marro@upc.edu, luis.miguel.llanes@upc.edu
}

\section{ABSTRACT}

In this work, the mechanical behavior of the coated ADI system is studied. For this purpose, single layer Ti and bilayer Ti/TiN and TiAl/TiAlN coatings, with different thicknesses, were deposited by the PVD technique of cathodic arc deposition on high strength ADI substrates using industrial and experimental devices.

The characterization of the coatings includes the measurement of the layer thicknesses by the spherical abrasion method, the determination of existing phases and residual stresses by $\mathrm{x}$-ray diffraction and the evaluation of the surface topography using a stylus profilometer. The analysis of the mechanical properties of the coatings comprises the measurement of the surface hardness by micro indentation tests and the evaluation of the scratch resistance. The scratch tests were performed on a scratch tester equipped with a Rockwell indenter. A progressive load from 1 to $100 \mathrm{~N}$, a load rate of $99 \mathrm{~N} / \mathrm{min}$, a speed of $5 \mathrm{~mm} / \mathrm{min}$ and a scratch length of $5 \mathrm{~mm}$ were employed. The influence of the coatings characteristics on the scratch resistance of the coated samples and the friction coefficients obtained are evaluated.

The results show that Ti coated samples had tensile residual stresses, the lowest surface hardness and the lowest critical loads for scratch adhesion strength. The samples coated with Ti/TiN and TiAl/TiAlN had highly compressive residual stresses and the highest critical loads, while the hardness was higher for $\mathrm{TiAl} / \mathrm{TiAlN}$. On the other hand, the evolution of the friction coefficient was similar for all the coated samples.

Keywords: Austempered ductile iron, PVD coatings, mechanical behavior.

\section{INTRODUCTION}

Austempered ductile iron (ADI) is increasingly being used for the manufacturing of mechanical components given the wide range of mechanical properties achievable after the proper adjustment of the chemical composition and heat treatment parameters, as well as its advantageous features if compared to high-strength cast steels, such as its lower cost and weight, greater flexibility in parts design and comparable tensile strength [1].

Ausferritic microstructure comprises a fine mixture of acicular ferrite and metastable austenite of high carbon content. Austenite is retained at room temperature because bainitic ferrite growth increases the local carbon content of the adjacent austenite, so decreasing martensite start temperature (Ms) to below room temperature. Provided sufficient temperature and time is given, austenite can lower its energy by transforming itself into a mixture of ferrite and cementite, thereby deteriorating the mechanical properties of the material [2].

On the other hand, it is widely recognized that the performance of mechanical components subjected to wear, fatigue and/or corrosion is strongly dependent on the properties and characteristics of their surface, 
mainly hardness, surface roughness, friction coefficient and residual stresses, all of them improvable by surface treatments. Notwithstanding this, any surface treatment involving ADI exposure to high temperature during long periods could activate the decomposition mechanisms of retained austenite previously described.

The deposition of thin-hard films by physical vapor deposition (PVD) is an effective means of optimizing the mechanical properties of heat treated parts. The low processing temperature of the PVD process $\left(200\right.$ to $\left.500^{\circ} \mathrm{C}\right)$ and relatively short exposure times, as compared to other surface treatments, encourages its use on ADI parts without damaging their microstructure.

Ductile interlayers (e.g. Ti, $\mathrm{Cr}, \mathrm{Zr}, \mathrm{Nb}$, etc.) have often been used as an alternative to improve the adhesion and wear properties of ceramic-based coated systems [3-5]. The introduction of two or more layers provides barriers to crack propagation [6]. Also, ductile interlayers might improve the load-bearing capacity as they provide a better stress distribution from the coating to the substrate [7]. Consequently, the introduction of an interlayer could improve the mechanical behavior of TiN and TiAlN coated ADI by reducing the properties mismatch between substrate and coating.

The bibliographic data referred to the mechanical behavior of PVD coated ADI are very scarce. However, several authors have accounted for improvements in corrosion resistance [8,9]. More recent studies have reported that duplex treatments, using electroless nickel as interlayer, provide better performance against corrosion than monolithic coatings do [10, 11]. In all the studies, processing temperatures of up to $300^{\circ} \mathrm{C}$ were used and no deterioration of ADI microstructure was reported.

Moreover, the authors of the present work found a combination of industrial-use processing parameters producing PVD TiN and CrN coatings of acceptable characteristics as far as coating thickness, hardness, residual stresses and adhesion are concerned, causing no significant deterioration of ADI microstructure. Additionally, the analysis of the effects of the substrate characteristics on coating properties evidenced little influence of the austempering temperature and nodule count [12-14].

In this work, single layer Ti and bilayer Ti/TiN and TiAl/TiAlN coatings, with different thicknesses, are deposited by the PVD technique of cathodic arc deposition (CAD) on high strength ADI substrates using industrial and experimental devices, and the mechanical behavior of the coated ADI system is studied.

\section{MATERIALS AND METHODS}

\subsection{Substrate material and samples preparation}

The experimental ductile iron used in this work was produced in a $55 \mathrm{~kg}$ middle-frequency induction furnace $(3 \mathrm{KHz})$. The melt was conventionally nodulized and inoculated [12]. The melt was poured into Y-blocks of $13 \mathrm{~mm}$. The chemical composition of the iron in wt. \%, analyzed by an optical emission spectrometer, was $3.35 \% \mathrm{C} ; 2.87 \% \mathrm{Si} ; 0.13 \% \mathrm{Mn} ; 0.015 \% \mathrm{~S} ; 0.032 \% \mathrm{P} ; 0.043 \% \mathrm{Mg} ; 0.76 \% \mathrm{Cu} ; 0.57 \% \mathrm{Ni}$ and $\mathrm{Fe}$ balanced. The nodule count of the Y-blocks was about $300 \mathrm{nod} / \mathrm{mm}^{2}$, with an average nodule diameter of 20 $\mu \mathrm{m}$. Nodularity exceeded $90 \%$ in all cases according to the ASTM A247 standard.

The Y-blocks were cut and machined in order to obtain prismatic samples of nominal dimensions 30x30x4 mm approximately. The samples were subjected to an austempering heat treatment in order to obtain a high resistance ADI. The heat treatment consisted in an austenitising at $910{ }^{\circ} \mathrm{C}$ for $120 \mathrm{~min}$, an austempering in a salt bath at $280{ }^{\circ} \mathrm{C}$ for $90 \mathrm{~min}$, and a subsequent air cooling to room temperature. The average Brinell hardness obtained was $420 \mathrm{HBW}_{2.5 / 187.5}$.

ADI samples were surface finished by conventional surface grinding, carried out on a horizontalspindle (peripheral) surface grinder using industrial-use cutting conditions. Three roughing passes and one finishing pass were performed on each sample in order to attain a low surface roughness. A vitrified wheel with $\mathrm{SiC}$ abrasive grains, identified as IC36/46I/J5V9, was employed. A 5\% aqueous solution of soluble oil was used as cooling fluid.

\subsection{Coating process}

The coatings were deposited by CAD in experimental and industrial devices using sets of processing parameters specifically designed for ADI in order to avoid its microstructural degradation. [16]. Prior to deposition, the substrates were thoroughly degreased, ultrasonically cleaned, rinsed with alcohol and dried with warm air. Inside the deposition chamber, the substrates were cleaned once again by bombardments with energetic ions to ensure a good adhesion of the coatings.

Single layer Ti and bilayer Ti/TiN coatings were deposited using an experimental device (EXP). The deposition times were adjusted to obtain single layer Ti coatings with nominal thicknesses of $0.3 \mu \mathrm{m}$ and 0.6 
$\mu \mathrm{m}$, and bilayer Ti/TiN coatings with a Ti interlayer of $0.3 \mu \mathrm{m}$ and TiN layers of $0.7 \mu \mathrm{m}$ and $1.5 \mu \mathrm{m}$. On the other hand, bilayer Ti/TiN and TiAl/TiAlN coatings were deposited using an industrial device (IND). The deposition time was adjusted to obtain an overall thickness of the Ti/TiN coating of about $1 \mu \mathrm{m}$ and was kept constant for TiAl/TiAlN. Table 1 lists the process parameters used to deposit the coatings.

Table 1: Process parameters used to deposit the coatings.

\begin{tabular}{l|l|l|l|l|l|l}
\hline COATING & Ti A & Ti B & Ti/TiN A & Ti/TiN B & Ti/TiN C & TiAI/TiAIN \\
\hline Device & EXP & EXP & EXP & EXP & IND & IND \\
\hline Target & $\mathrm{Ti}$ & $\mathrm{Ti}$ & $\mathrm{Ti}$ & $\mathrm{Ti}$ & $\mathrm{Ti}$ & TiAl 50/50 \\
\hline Substrate-target distance $(\mathrm{mm})$ & 200 & 200 & 200 & 200 & 200 & 200 \\
\hline Substrate bias voltage $(\mathrm{V})$ & -130 & -130 & -130 & -130 & -175 & -175 \\
\hline Discharge current $(\mathrm{A})$ & 100 & 100 & $100 / 80$ & $100 / 80$ & 60 & 60 \\
\hline Chamber pressure during discharge $(\mathrm{Pa})$ & 0.001 & 0.001 & $0.001 / 0.02$ & $0.001 / 0.02$ & 2 & 2 \\
\hline Substrate temperature $\left({ }^{\circ} \mathrm{C}\right)$ & 300 & 300 & 300 & 300 & 300 & 300 \\
\hline Discharge time (min) & 5 & 10 & $5 / 16$ & $5 / 35$ & $10 / 50$ & $10 / 50$ \\
\hline
\end{tabular}

\subsection{Substrates and coatings characterization}

Optical microscopy was employed to examine the microstructure of ADI before and after coating depositions and the surface characteristics of the samples. Metallographic samples were prepared by using standard techniques. Metallographic etching was performed with Nital $2 \%$.

$\mathrm{X}$-ray diffraction (XRD) was used for phase identification and for residual stress measurements. A Phillips XPERT-PRO diffractometer was employed with $\mathrm{Cu} \mathrm{K} \alpha$ radiation $(\lambda=1.54187 \AA)$. XRD patterns for phase identification were recorded in a $2 \theta$ range from $30^{\circ}$ to $90^{\circ}$ in steps of $0.02^{\circ}$ and with a counting time of 1 second per step.

Residual stress measurements were conducted using the $\sin ^{2} \psi$ method, with the assumption of a biaxial stress state. Fe- $\alpha$ (222), Ti- $\alpha$ (300), TiN (422) and TiAlN (422) reflections were used to measure the strains in the uncoated and coated samples, respectively. The $2 \theta$ angle ranged from $134^{\circ}$ to $140^{\circ}$ for Fe- $\alpha$, from $121^{\circ}$ to $133^{\circ}$ for $\mathrm{Ti}$, from $120^{\circ}$ to $132^{\circ}$ for TiN and from $122^{\circ}$ to $134^{\circ}$ for TiAlN with a $2 \theta$ step of $0.05^{\circ}$ and a collection time of 5 seconds per step. The X-ray elastic constants (XEC's) used to calculate stresses in uncoated and coated samples were extracted from bibliographic data [15-17].

A stylus profilometer (Taylor Hobson Surtronic 3+) with a $4 \mathrm{~mm}$ evaluation length (cut off, $0.8 \mu \mathrm{m}$ ) was used to measure the arithmetic average roughness $(\mathrm{Ra})$ of the uncoated and coated samples. Coating thickness was measured by means of the spherical abrasion method.

\subsection{Mechanical behavior analysis}

The analysis of the mechanical properties of the coatings comprises the measurement of the surface hardness by microindentation tests and the evaluation of the scratch resistance.

The microindentation tests were performed using a Knoop indenter and a $0.015 \mathrm{~kg}$ load. The scratch tests were performed on a CSM Revetest scratch-tester equipped with a Rockwell indenter. The coatings were tested using a progressive load ranging from $1 \mathrm{~N}$ to $100 \mathrm{~N}$, a loading rate of $99 \mathrm{~N} / \mathrm{min}$, a speed of 5 $\mathrm{mm} / \mathrm{min}$ and a scratch length of $5 \mathrm{~mm}$. Critical loads were determined by post-tests optical microscopy. Two stages in the coating damage were considered, the first delamination within the track (Lc1) and massive delamination (Lc2) [18]. The evolution of the friction coefficients during the scratch tests was also evaluated.

\section{RESULTS}

\subsection{Substrates and coatings characteristics}

Figure 1 compares, as an example, the microstructure of ADI before and after the Ti/TiN C process. 


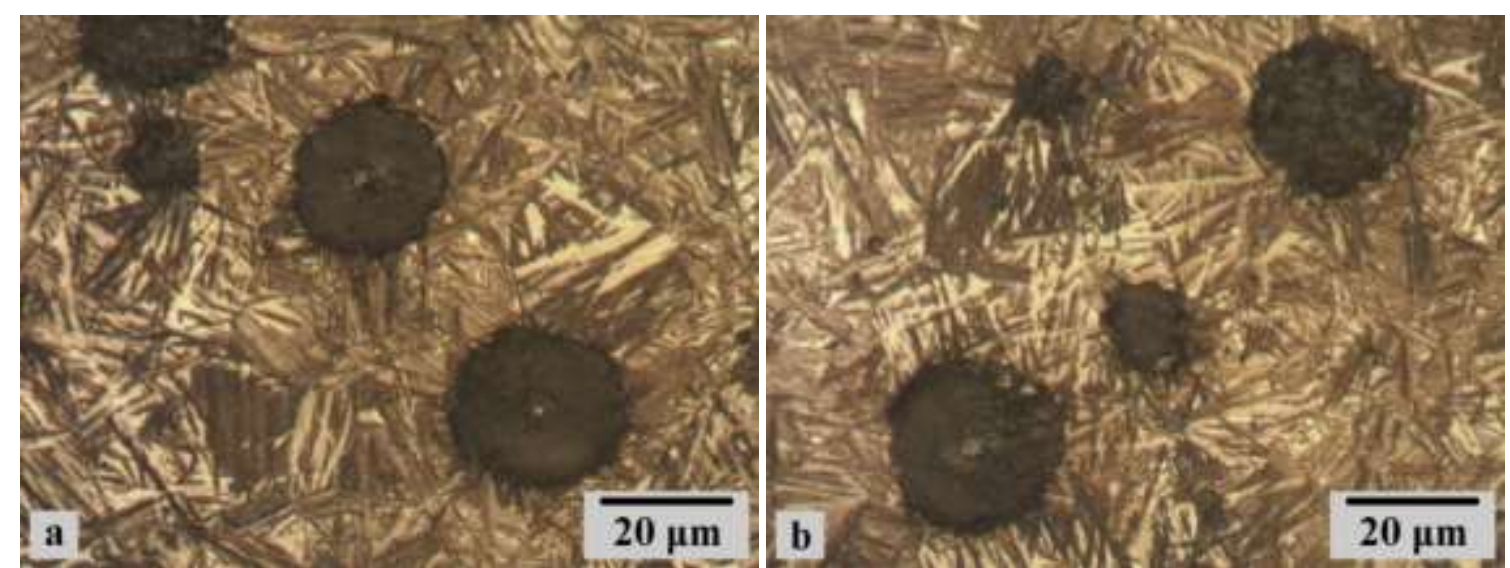

Figure 1: Microstructure of ADI samples: (a) before deposition, (b) after Ti/TiN C process.

Figure 2 illustrates the $\mathrm{x}$-ray diffraction patterns of the coated samples.
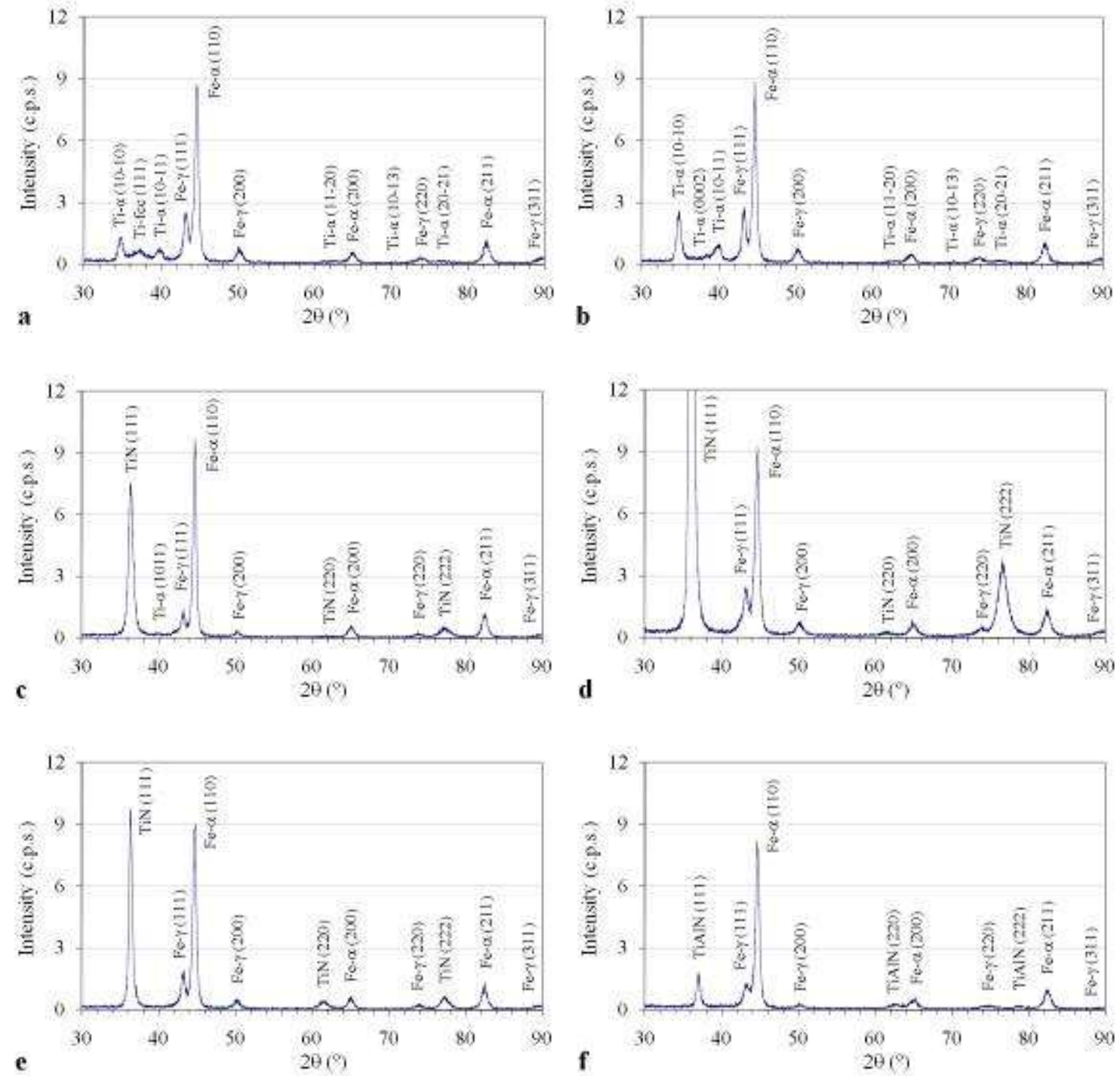

Figure 2: XRD patterns of the coated samples: (a) Ti A, (b) Ti B, (c) Ti/TiN A, (d) Ti/TiN B, (e) Ti/TiN C, (f) TiAl/TiAlN.

Figure 3 shows, as an example, the surface characteristics of ADI, Ti/TiN A and Ti/TiN C samples. 

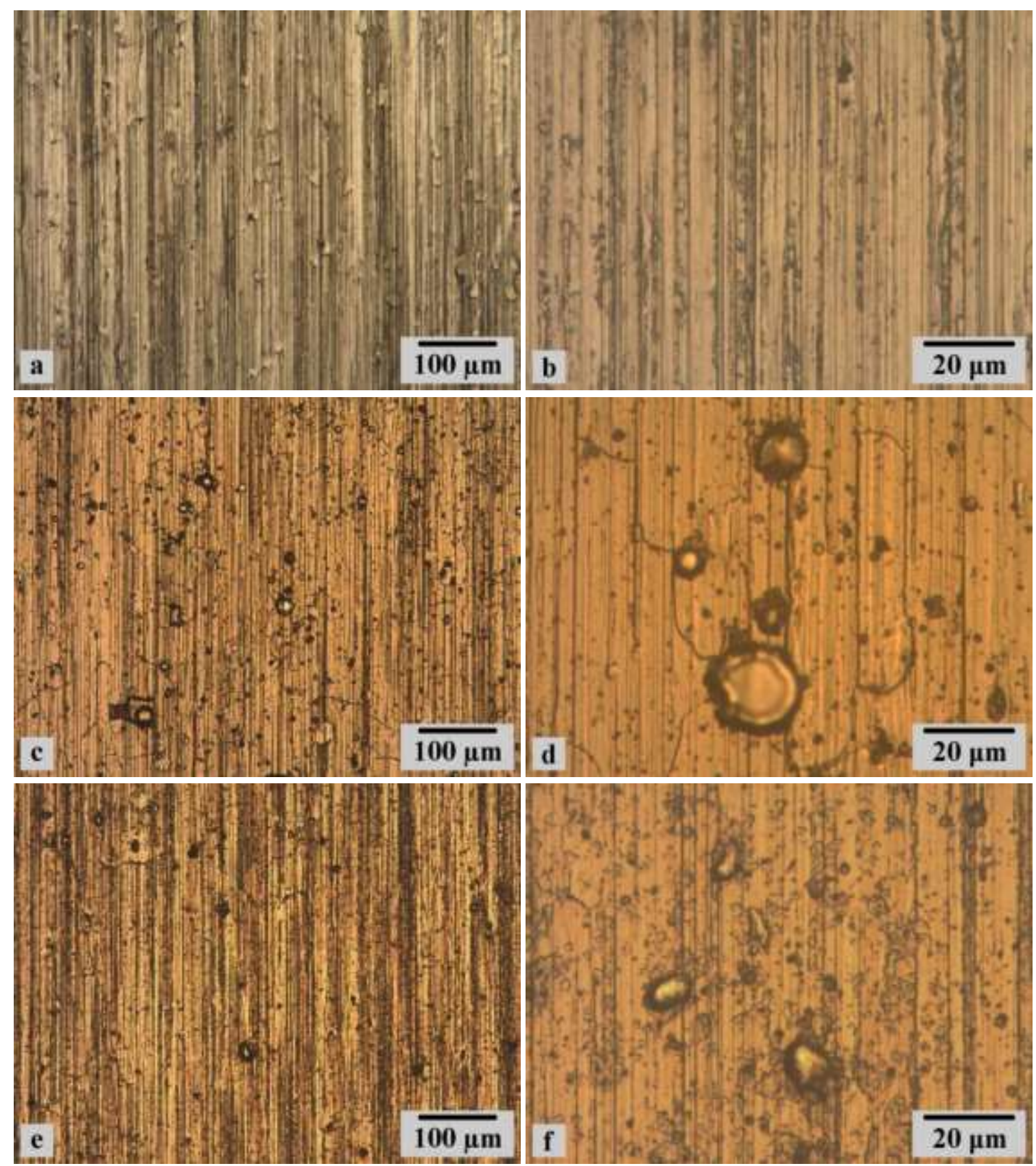

Figure 3: Surface characteristics of ADI samples: (a) before deposition 100x, (b) before deposition 500x, (c) after Ti/TiN A process 100x, (d) after Ti/TiN A process 500x, (e) after Ti/TiN C process 100x, (f) after Ti/TiN C process 500x.

Table 2 lists the properties of the coated samples, such as layer thickness, arithmetic average roughness $(\mathrm{Ra})$ and residual stresses (RS). The surface roughness and RS of the uncoated samples are listed in the first row.

Table 2: Characteristics of the uncoated and coated samples.

\begin{tabular}{l|l|l|l|l}
\hline \multirow{2}{*}{ SAMPLE } & \multicolumn{2}{|l|}{ THICKNESS $(\boldsymbol{\mu m})$} & \multirow{2}{*}{ Ra $(\boldsymbol{\mu m})$} & \multirow{2}{*}{ RS $(\mathrm{GPa})$} \\
\cline { 2 - 4 } & INTERLAYER & OUTER LAYER & & \\
\hline ADI & -- & - & $0.21 \pm 0.03$ & $-0.41 \pm 0.04$ \\
\hline Ti A & -- & $0.29 \pm 0.03$ & $0.37 \pm 0.06$ & $0.25 \pm 0.08$ \\
\hline Ti B & -- & $0.64 \pm 0.05$ & $0.53 \pm 0.06$ & $0.26 \pm 0.07$ \\
\hline Ti/TiN A & $0.29 \pm 0.02$ & $0.73 \pm 0.02$ & $0.34 \pm 0.06$ & $-6.06 \pm 0.13$ \\
\hline
\end{tabular}




\begin{tabular}{l|l|l|l|l}
\hline Ti/TiN B & $0.32 \pm 0.02$ & $1.47 \pm 0.03$ & $0.38 \pm 0.03$ & $-6.86 \pm 0.26$ \\
\hline Ti/TiN C & $0.14 \pm 0.03$ & $0.85 \pm 0.07$ & $0.28 \pm 0.02$ & $-4.27 \pm 0.11$ \\
\hline TiAl/TiAlN & $0.21 \pm 0.01$ & $1.16 \pm 0.02$ & $0.27 \pm 0.02$ & $-5.95 \pm 0.29$ \\
\hline
\end{tabular}

\subsection{Mechanical behavior}

Table 3 lists the surface hardness of the uncoated and coated samples and the results of the scratch tests.

Table 3: Mechanical properties of the uncoated and coated samples.

\begin{tabular}{l|l|l|l}
\hline \multirow{2}{*}{ SAMPLE } & $\begin{array}{l}\text { SURFACE } \\
\text { HARDNESS }\end{array}$ & \multicolumn{2}{l}{ CRITICAL LOADS (N) } \\
\cline { 2 - 4 } & (HK $\left._{\mathbf{0 . 0 1 5}}\right)$ & Lc1 & Lc2 \\
\hline ADI & $620 \pm 109$ & -- & -- \\
\hline Ti A & $678 \pm 70$ & $7.0 \pm 0.2$ & $27.3 \pm 5.0$ \\
\hline Ti B & $708 \pm 67$ & $6.5 \pm 0.1$ & $21.7 \pm 2.5$ \\
\hline Ti/TiN A & $1197 \pm 95$ & $22.6 \pm 1.0$ & $44.3 \pm 3.3$ \\
\hline Ti/TiN B & $1576 \pm 120$ & $28.1 \pm 1.8$ & $48.3 \pm 2.2$ \\
\hline Ti/TiN C & $1238 \pm 113$ & $28.8 \pm 1.1$ & $52.7 \pm 6.6$ \\
\hline TiAl/TiAlN & $1910 \pm 97$ & $23.2 \pm 1.7$ & $44.8 \pm 5.0$ \\
\hline
\end{tabular}

Figure 4 shows representative images of the tracks resulting from the scratch tests. The points associated with the different critical loads are indicated on the image of each scratch track.
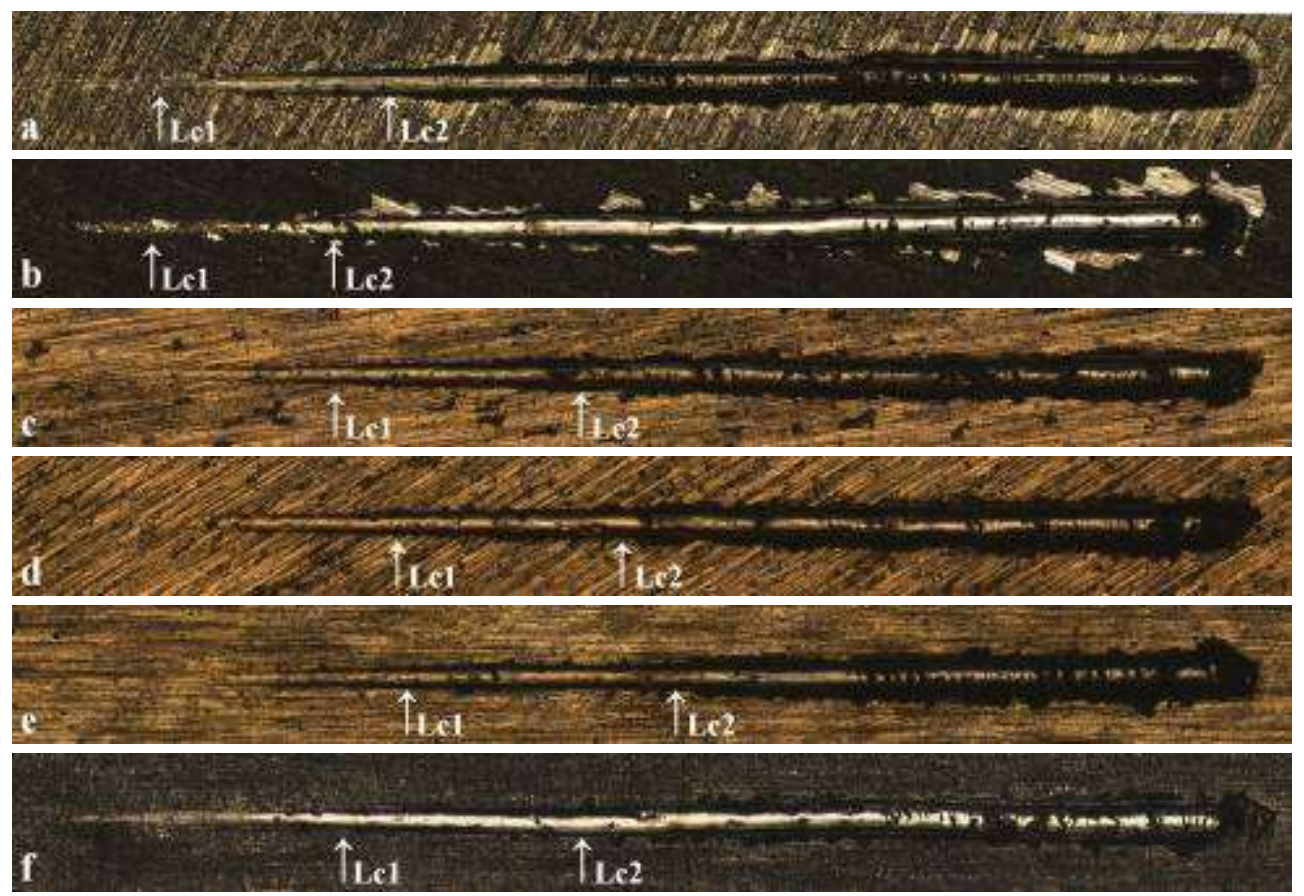

\begin{tabular}{|lccccc|}
\hline $1.00 \mathrm{~N}$ & 20.79 & 40.58 & $60^{\prime} 37$ & 80.16 & 99.95 \\
\hline $0.00 \mathrm{~mm}$ & 1.00 & 200 & 3.00 & 4.00 & 5.00 \\
\hline
\end{tabular}

Figure 4: Representative images of the tracks resulting from the scratch tests: (a) Ti A, (b) Ti B, (c) Ti/TiN A, (d) Ti/TiN B, (e) Ti/TiN C, (f) TiAl/TiAlN

Figure 5 shows, as an example, micrographs of the scratch track of Ti/TiN B sample which exhibit in detail the different damage stages considered, first delamination within the track (Lc1) and massive delamination (Lc2). 


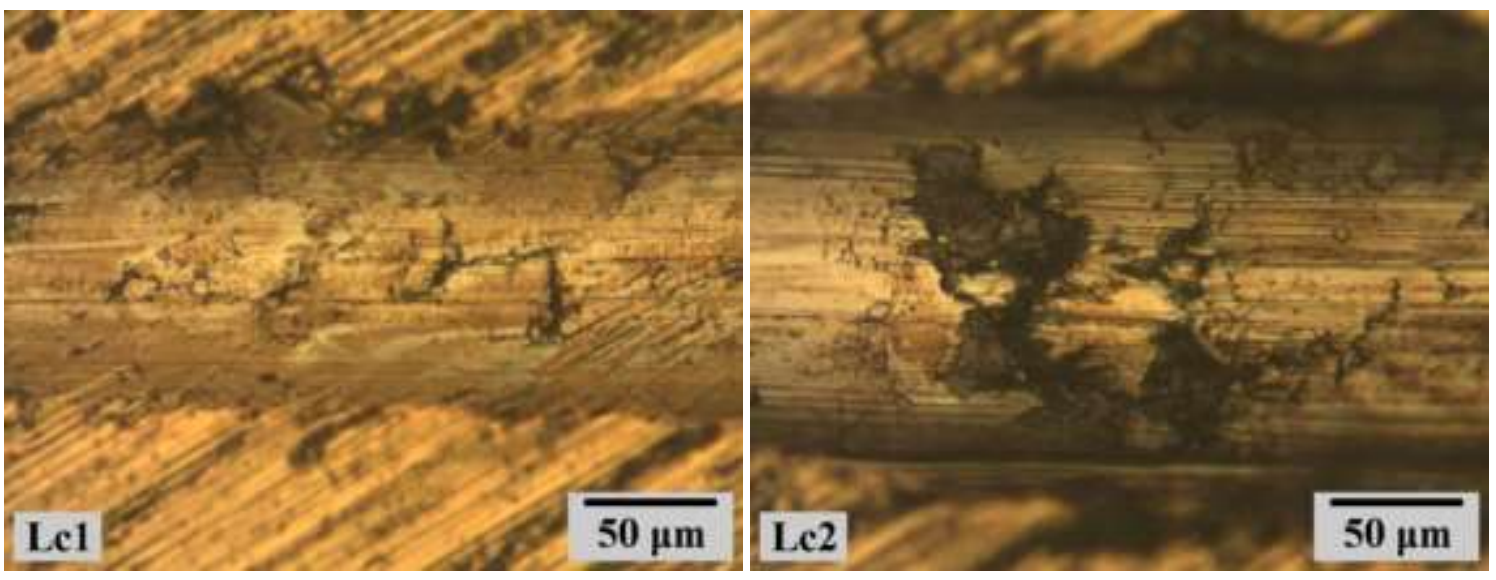

Figure 5: Micrographs of the scratch track of Ti/TiN B sample showing in detail the different damage stages considered.

Figure 6 shows the friction coefficient evolution for the different coating variants as a function of the scratch length.

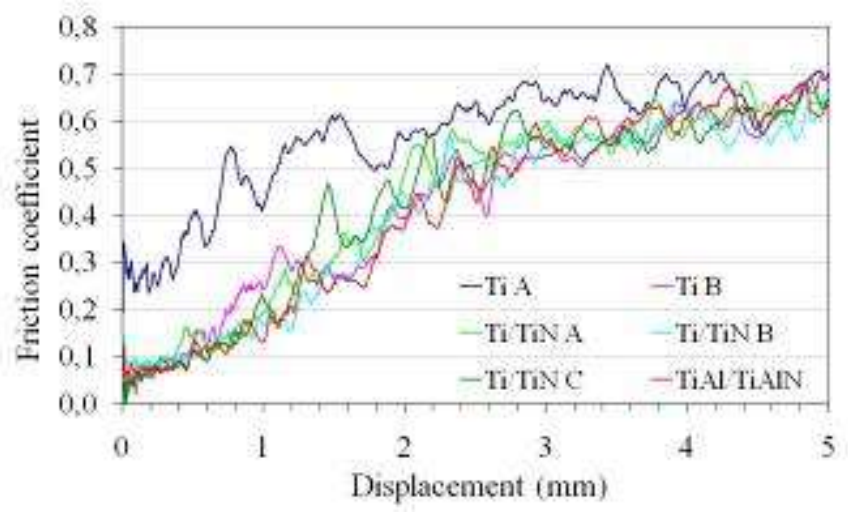

Figure 6: Friction coefficient evolution for the different coating variants analyzed.

\section{DISCUSSION}

\subsection{Substrates and coatings characteristics}

The micrographs of Figure 1 show that the microstructures of ADI before and after coating deposition are analogous to each other. In addition, the austenite content and the surface hardness before and after depositions remained close to $18 \mathrm{vol} \%$ and $620 \mathrm{HK}_{0.015}$, respectively, indicating that the coating process did not produce changes in the microstructure of ADI.

The XRD patterns of Figure 2 reveal not only the main diffraction peaks of the coatings but also some peaks of the ferrite $(\mathrm{Fe}-\alpha)$ and austenite $(\mathrm{Fe}-\gamma)$ phases which belong to the substrates, since the penetration depth of the $\mathrm{x}$-rays is greater than the coatings thickness.

The XRD patterns of the single layer Ti coatings exhibited peaks related to the hexagonal close packed (hcp) Ti crystal structure, which is commonly denoted as $\alpha$ phase. On the other hand, the thinnest single layer Ti coating (Ti A, see Table 2) exhibited an additional peak which could be associated with the face centered cubic (fcc) Ti phase [19]. According to previous studies [19, 20], the presence of the fcc Ti phase was found to be dependent on the film thickness. The critical thickness above which no fcc Ti was observed was estimated in $\sim 0.3 \mu \mathrm{m}$.

The XRD patterns of the bilayer Ti/TiN coatings revealed the main diffraction peaks of TiN, having a $\mathrm{NaCl}$-type structure, which grew with a preferred orientation of (111) planes parallel to the samples surface. This strong (111) preferred orientation has been commonly observed for TiN coatings deposited by PVD techniques $[21,22]$. On the other hand, only the Ti/TiN coating with the thinnest TiN layer (Ti/TiN A, see Table 2) exhibited some peaks associated to the Ti- $\alpha$ phase. In addition, it can be seen an increase in the relative intensity of the TiN peaks as the TiN layer thickness increases (see Table 2). 
The XRD pattern of the bilayer TiAl/TiAlN coating revealed the main diffraction peaks of TiAlN, also with a NaCl-type structure. According to a previous study [23], the crystal structure of $\mathrm{Ti}_{1-\mathrm{X}} \mathrm{Al}_{\mathrm{X}} \mathrm{N}$ depends on the $\mathrm{Al}$ content $(\mathrm{X})$, changing from the $\mathrm{NaCl}$-type structure to a hexagonal structure at $\mathrm{X}=0.6-$ 0.7. In addition, nor Ti neither $\mathrm{Al}$ peaks were recorded.

The micrographs of Figures $3 \mathrm{a}$ and $3 \mathrm{~b}$ show that there are no graphite nodules exposed at the surface of ADI substrates whose average diameter is close to $20 \mu \mathrm{m}$, as it can be seen in Figure 1. According to a previous study [24], this feature can be ascribed to the plastic deformation of the metallic matrix, inherent to the abrasive cutting of grinding, which covers the surface nodules with a thin metallic layer. The micrographs of Figures $3 \mathrm{c}$ to $3 \mathrm{f}$ show macroparticles of different size in the surface of the coated samples. The presence of macroparticles is a characteristic phenomenon of the CAD process [25-27]. It can be noted that the amount and size of macroparticles is higher for the coatings deposited in the experimental device. According to previous studies [28, 29], this behavior can be associated with the lower discharge current and the higher chamber pressure employed in the industrial processes.

From Table 2 it can be seen that the ADI substrates exhibit an average Ra value of $0.21 \mu \mathrm{m}$ and compressive residual stresses, with an average value of $-0.41 \mathrm{GPa}$.

From Tables 1 and 2 it can be seen that for the experimental device, the deposition rate of Ti (in the range $0.058-0.064 \mu \mathrm{m} / \mathrm{min}$ ) is a little higher than that of $\mathrm{TiN}$ (in the range $0.042-0.046 \mu \mathrm{m} / \mathrm{min}$ ). For the industrial device, it can be seen that the deposition rates of Ti and TiN are very close each other (between 0.014 and $0.017 \mu \mathrm{m} / \mathrm{min}$ ) and that they are lower than those of the experimental device. In addition, the deposition rates of TiAl and TiAlN are also very close each other $(0.021$ and $0.023 \mu \mathrm{m} / \mathrm{min})$ and a little higher than those of Ti and TiN.

Regarding surface roughness, the coated samples present higher Ra values than uncoated ADI (see Table 2). The increase in $\mathrm{Ra}$ is attributed to the presence of macroparticles (protrusions) in the surface of the coated samples [29, 30]. The Ra values of the films deposited in the experimental device increase with film thickness for the monolayer Ti films and do not vary significantly in the case of Ti/TiN films. On the other hand, the Ra values of the samples coated using the experimental device are noticeably higher than those of the samples coated using the industrial device. This behavior is consistent with the macroparticle content observed for each device and indicates that a smaller amount and size of macroparticles induces a lower surface roughness.

Regarding RS of the films deposited in the experimental device (see Table 2), the single layer Ti films exhibit tensile RS, with an average value close to $0.25 \mathrm{GPa}$ while the bilayer Ti/TiN films exhibit highly compressive RS, with average values between -6.06 and $-6.86 \mathrm{GPa}$. In addition, the RS level of the Ti/TiN films increases as film thickness does while that of the Ti films remains constant. The influence of film thickness on RS level is somewhat unclear since some authors reported a decrease of the compressive RS as film thickness increased [31] and other authors reported the opposite behavior [32] or no influence [33]. The $\mathrm{RS}$ of the films deposited using the industrial device are also compressive, with average values of -4.27 and $5.95 \mathrm{GPa}$ for $\mathrm{Ti} / \mathrm{TiN}$ and $\mathrm{TiAl} / \mathrm{TiAlN}$, respectively. It can be seen that the TiAl/TiAlN films exhibit higher RS. This behavior can be ascribed to the addition of Al into the TiN lattice, which increases the number and/or volume of defects created during film growth, hindering the dislocations movement and inducing strain in the film $[34,35]$. On the other hand, it can be noted that the RS of the Ti/TiN films deposited in the industrial device are lower than those of the Ti/TiN films deposited in the experimental device. This behavior can be ascribed to the different processing parameters used in each device, mainly bias voltage and chamber pressure $[36,37]$.

\subsection{Mechanical behavior}

From Table 3 it can be seen that the surface hardness of the Ti coated samples is very similar to that of uncoated ADI and lower than the surface hardness of the Ti/TiN and TiAl/TiAlN coated samples. It also can be seen that the surface hardness of the Ti/TiN coated samples increases as TiN layer thickness increases. This behavior can be ascribed to the fact that the indentation response of a coated sample depends on the film thickness and the characteristics of substrates and coatings [38]. Thus, for a given applied load, a lower film thickness leads to a greater influence of the substrate on the surface hardness of a coated sample. In addition, the different process parameters used in the experimental and industrial devices do not produce significant changes in the surface hardness of the Ti/TiN coated samples with the same film thickness (Ti/TiN A and $\mathrm{Ti} / \mathrm{TiN} \mathrm{C}$ ). On the other hand, the hardness of the TiAl/TiAlN films turned out to be higher than that of the $\mathrm{Ti} / \mathrm{TiN}$ ones. This behavior can also be ascribed to the incorporation of $\mathrm{Al}$ into the TiN lattice without change of the NaCl-type structure [34, 35]. 
Regarding the scratch tests results (see Table 3), it can be seen that the critical loads of the single layer coatings are lower than those of the bilayer coatings. In the case of the single layer coatings (Ti A and Ti B), no significant differences in the critical loads (Lc1 and Lc2) are observed. In the case of the bilayer coatings deposited using the experimental device, the critical loads of the Ti/TiN A samples are slightly higher than those of the Ti/TiN B samples. According to previous studies [39-43], the adhesion strength increases as coating thickness and compressive RS increase and as surface roughness decreases. Consequently, the similar performance of the single layer Ti coatings can be ascribed to the higher surface roughness of the thicker Ti layer and the higher average critical loads of the Ti/TiN B samples as compared to those of the Ti/TiN A can be ascribed to the combined effect of thicker film thickness and higher RS level. On the other hand, if the performance of the Ti/TiN coatings deposited using industrial and experimental devices is compared, it can be seen that the critical loads of the coating deposited using the industrial device (Ti/TiN C) are higher. This behavior can be ascribed to the lower surface roughness of the Ti/TiN $\mathrm{C}$ coated samples despite their lower compressive stress level. Finally, if the performance of the coatings deposited using the industrial device is compared, it can be seen that the critical loads of the TiAl/TiAlN are lower. According to previous studies $[44,45]$, this behavior can be ascribed to a higher elastic modulus of the TiAl/TiAlN coating with respect to $\mathrm{Ti} / \mathrm{TiN}$, since a greater elastic modulus mismatch between substrate and coating increases the probability of coatings to suffer cracking and/or delamination under the effects of the plastic strain accumulated in ADI substrates during tests.

From Figure 3, it can be seen that the evolution of the friction coefficient is quite similar for all the coated samples, except for the case of the samples coated with the thinnest Ti film (Ti A) which show higher values than those of the rest of the samples during almost the entire displacement distance. Before reaching Lc1, all the coatings are undamaged and the friction coefficient values are close to 0.3 for the Ti A samples, and ranged from 0.1 to 0.2 for rest for the samples. Between Lc1 and Lc2, the friction coefficient curves show a chaotic behavior related to the coating damage events. At the end of the displacement distance, after reaching Lc2, the indenter scratches the substrates and the samples exhibit a friction coefficient value close to 0.7 , which correspond to the friction coefficient of ADI against diamond.

\section{CONCLUSIONS}

Single layer Ti and bilayer Ti/TiN and TiAl/TiAlN coatings, with different thicknesses, were deposited by CAD on high strength ADI substrates and the characteristics and mechanical behavior of the coated ADI system was studied. Based on the results, within the thickness range analyzed and the test conditions used, the following conclusions can be drawn:

1. The surface roughness of the coated samples is related to the macroparticle content which depends on the processing parameters employed to deposit the films. A lower discharge current and a higher chamber pressure induce a lower roughness.2. The residual stress state of the coated samples depends on the coating material and the deposition conditions. Higher bias voltages and chamber pressures induce lower compressive residual stresses.

3. The surface hardness of the coated samples depends on the coating material and its thickness. The different process parameters used in the experimental and industrial devices do not produce significant changes in the hardness of the coated samples.

4. The critical loads for scratch adhesion of the single layer and bilayer coatings depend of the combined effect of several variables such as coating thickness, surface roughness and residual stresses. The mismatch in elastic properties between substrate and coatings seems to play an important role as well.

5. The evolution of the friction coefficient during scratch tests seems to be mainly related to the plastic strain accumulated in the substrates as scratch distance increases than to the mechanical and physical characteristics of the coatings.

\section{ACKNOWLEDGMENTS}

The authors wish to thank the company Sudosilo S.A. for its generous collaboration in industrial coatings deposition. The financial support granted by the CONICET (Grant No. PIP 11220120100468CO), the ANPCYT (Grant No. PICT 2013-2630) the University of Buenos Aires (Grant No. PID 20020110100161) and the National University of Mar del Plata (Grant No. 15/G394) is also gratefully acknowledged.

\section{BIBLIOGRAPHY}

[1] DUCTILE IRON GROUP, Ductile Iron Data for Design Engineers, Section IV - Austempered Ductie 
Iron, Montreal, Quebec, Canadá, Rio Tinto Iron \& Titanium, Inc., 1990.

[2] MASSONE, J. M., BOERI, R. E., SIKORA, J. A., "Changes in the structure and properties of ADI on exposure to high temperature", International Journal of Cast Metals Research, v. 9, pp. 79-92, 1996.

[3] HONG, Y. S., KWON, S. H., WANG, T., et al., "Effects of Cr interlayer on mechanical and tribological properties of Cr-Al-Si-N nanocomposite coating", Transactions of Nonferrous Metals Society of China, v. 21, Supplement 1, pp. s62-s67, 2011.

[4] FONTALVO, G. A., DANIEL, R., MITTERER, C., "Interlayer thickness influence on the tribological response of bi-layer coatings", Tribology International, v. 43, n. 1-2, pp. 108-112, 2010.

[5] TANG, J., FENG, L., ZABINSKI, J. S., "The effects of metal interlayer insertion on the friction, wear and adhesion of TiC coatings", Surface and Coatings Technology, v. 99, n. 3, pp. 242-247, 1998.

[6] BULL, S. J., JONES, A. M., "Multilayer coatings for improved performance", Surface and Coatings Technology, v. 78, n. 1-3, pp. 173-184, 1996.

[7] DIAO, D. F., SAWAKI, Y., SUZUKI, H., "Effect of interlayer on maximum contact stresses of hard coating under sliding contact", Surface and Coatings Technology, v. 86-87, Part 2, pp. 480-485, 1996.

[8] HSU, C.-H., LU, J.-K., LAI, K.-L., et al., "Erosion and corrosion behaviors of ADI deposited TiN/TiAlN coatings by cathodic arc evaporation", Materials Transactions, v. 46, n. 6, pp. 1417-1424, 2005.

[9] HSU, C. H., CHEN, M. L., LAI, K. L., "Corrosion resistance of TiN/TiAlN-coated ADI by cathodic arc deposition", Materials Science and Engineering: A, v. 421, n. 1-2, pp. 182-190, 2006.

[10] HSU, C.-H., CHEN, K.-L., LEE, C.-Y., et al., "Effects of low-temperature duplex coatings on corrosion behavior of austempered ductile iron", Surface and Coatings Technology, v. 204, n. 6-7, pp. 997-1001, 2009.

[11] HSU, C.-H., HUANG, K.-H., CHEN, Y.-T., et al., "The effect of electroless Ni-P interlayer on corrosion behavior of TiN-coated austempered ductile iron”, Thin Solid Films, v. 529, pp. 34-38, 2013.

[12] COLOMBO, D. A., ECHEVERRÍA, M. D., MONCADA, O. J., et al., "Characterisation of PVD-TiN coated austempered ductile iron: effects of nodule count and austempering temperature", ISIJ International, v. 51, n. 3, pp. 448-455, 2011.

[13] COLOMBO, D. A., ECHEVERRÍA, M. D., MONCADA, O. J., et al., "PVD TiN and CrN coated austempered ductile iron: analysis of processing parameters influence on coating characteristics and substrate microstructure", ISIJ International, v. 52, n. 1, pp. 121-126, 2012.

[14] COLOMBO, D. A., ECHEVERRÍA, M. D., MONCADA, O. J., et al., "Residual stress analysis in PVD coated austempered ductile iron", ISIJ International, v. 53, n. 3, pp. 520-526, 2013.

[15] MARTINSCHITZ, K. J., DANIEL, R., MITTERER, C., et al., "Stress evolution in CrN/Cr coating systems during thermal straining", Thin Solid Films, v. 516, n. 8, pp. 1972-1976, 2008.

[16] SMITHELLS, C. J., BRANDES, E. A., Metals Reference Book, 5th Edition, London, UK, Butterworth, 1976.

[17] ZHANG, M., HE, J., "Ab-initio calculation of elastic constants of TiN", Surface and Coatings Technology, v. 142-144, pp. 125-131, 2001.

[18] OU, Y. X., LIN, J., TONG, S., et al., "Structure, adhesion and corrosion behavior of CrN/TiN superlattice coatings deposited by the combined deep oscillation magnetron sputtering and pulsed $\mathrm{dc}$ magnetron sputtering", Surface and Coatings Technology, v. 293, pp. 21-27, 2016.

[19] FAZIO, M., VEGA, D., KLEIMAN, A., et al., "Study of the structure of titanium thin films deposited with a vacuum arc as a function of the thickness", Thin Solid Films, v. 593, pp. 110-115, 2015.

[20] CHAKRABORTY, J., KUMAR, K., RANJAN, R., et al., "Thickness-dependent fcc-hcp phase transformation in polycrystalline titanium thin films", Acta Materialia, v. 59, n. 7, pp. 2615-2623, 2011.

[21] RYBIAK, R., FOUVRY, S., LISKIEWICZ, T., et al., "Fretting wear of a TiN PVD coating under variable relative humidity conditions - development of a "composite" wear law", Surface and Coatings Technology, v. 202, n. 9, pp. 1753-1763, 2008.

[22] YOON, S.-Y., KIM, J.-K., KIM, K. H., "A comparative study on tribological behavior of TiN and TiAlN coatings prepared by arc ion plating technique", Surface and Coatings Technology, v. 161, n. 2-3, pp. 237-242, 2002.

[23] KIMURA, A., KAWATE, M., HASEGAWA, H., et al., "Anisotropic lattice expansion and shrinkage of hexagonal TiAIN and CrAIN films", Surface and Coatings Technology, v. 169-170, pp. 367-370, 2003. 
[24] BRUNETTI, C., LEITE, M. V., PINTAUDE, G., "Effect of specimen preparation on contact fatigue wear resistance of austempered ductile cast iron", Wear, v. 263, n. 1-6, pp. 663-668, 2007.

[25] MCCLURE, G. W., "Plasma expansion as a cause of metal displacement in vacuum-arc cathode spots", Journal of Applied Physics, v. 45, n. 5, pp. 2078-2084, 1974.

[26] DAALDER, J. E., "Components of cathode erosion in vacuum arcs", Journal of Physics D: Applied Physics, v. 9, n. 16, pp. 2379, 1976.

[27] BOXMAN, R. L., GOLDSMITH, S., "Macroparticle contamination in cathodic arc coatings: generation, transport and control", Surface and Coatings Technology, v. 52, n. 1, pp. 39-50, 1992.

[28] HARRIS, S. G., DOYLE, E. D., WONG, Y. C., et al., "Reducing the macroparticle content of cathodic arc evaporated TiN coatings", Surface and Coatings Technology, v. 183, n. 2-3, pp. 283-294, 2004.

[29] TAI, C. N., KOH, E. S., AKARI, K., "Macroparticles on TiN films prepared by the arc ion plating process", Surface and Coatings Technology, v. 43-44, Part 1, pp. 324-335, 1990.

[30] LEE, J.-W., DUH, J.-G., WANG, J.-H., "Mechanical property evaluation of cathodic arc plasmadeposited CrN thin films on Fe-Mn-Al-C alloys", Surface and Coatings Technology, v. 168, n. 2-3, pp. 223230, 2003.

[31] CHOU, W.-J., YU, G.-P., HUANG, J.-H., "Mechanical properties of TiN thin film coatings on 304 stainless steel substrates", Surface and Coatings Technology, v. 149, n. 1, pp. 7-13, 2002.

[32] ZHAO, S.-S., YANG, Y., LI, J.-B., et al., "Effect of deposition processes on residual stress profiles along the thickness in (Ti,Al)N films", Surface and Coatings Technology, v. 202, n. 21, pp. 5185-5189, 2008.

[33] HUANG, J.-H., YANG, H.-C., GUO, X.-J., et al., "Effect of film thickness on the structure and properties of nanocrystalline $\mathrm{ZrN}$ thin films produced by ion plating", Surface and Coatings Technology, v. 195, n. 2-3, pp. 204-213, 2005.

[34] KARLSSON, L., HULTMAN, L., JOHANSSON, M. P., et al., "Growth, microstructure, and mechanical properties of arc evaporated TiCxN1-x $(0 \leq \mathrm{x} \leq 1)$ films", Surface and Coatings Technology, v. 126, n. 1, pp. 1-14, 2000.

[35] REITER, A. E., DERFLINGER, V. H., HANSELMANN, B., et al., "Investigation of the properties of Al1- $\mathrm{xCrxN}$ coatings prepared by cathodic arc evaporation", Surface and Coatings Technology, v. 200, n. 7, pp. 2114-2122, 2005.

[36] KLEER, G., KASSNER, R., MEYER, E. M., et al., "Effect of process parameters on the residual stresses and the wear behavior of aluminum nitride physical vapor deposition coatings", Surface and Coatings Technology, v. 54-55, pp. 167-172, 1992.

[37] LJUNGCRANTZ, H., HULTMAN, L., SUNDGREN, J. E., et al., "Ion induced stress generation in arcevaporated TiN films", Journal of Applied Physics, v. 78, n. 2, pp. 832-837, 1995.

[38] KORSUNSKY, A. M., MCGURK, M. R., BULL, S. J., et al., "On the hardness of coated systems", Surface and Coatings Technology, v. 99, n. 1-2, pp. 171-183, 1998.

[39] STEINMANN, P. A., TARDY, Y., HINTERMANN, H. E., "Adhesion testing by the scratch test method: The influence of intrinsic and extrinsic parameters on the critical load", Thin Solid Films, v. 154, n. 1-2, pp. 333-349, 1987.

[40] NIE, X., LEYLAND, A., SONG, H. W., et al., "Thickness effects on the mechanical properties of micro-arc discharge oxide coatings on aluminium alloys", Surface and Coatings Technology, v. 116-119, pp. 1055-1060, 1999.

[41] HUANG, Y.-C., CHANG, S.-Y., CHANG, C.-H., "Effect of residual stresses on mechanical properties and interface adhesion strength of SiN thin films", Thin Solid Films, v. 517, n. 17, pp. 4857-4861, 2009

[42] BAI, Y., XI, Y., GAO, K., et al., "Residual stress control in CrAlN coatings deposited on Ti alloys", Ceramics International, v. 44, n. 5, pp. 4653-4659, 2018.

[43] SKORDARIS, G., BOUZAKIS, K. D., KOTSANIS, T., et al., "Effect of PVD film's residual stresses on their mechanical properties, brittleness, adhesion and cutting performance of coated tools", CIRP Journal of Manufacturing Science and Technology, v. 18, pp. 145-151, 2017.

[44] HUANG, X., ETSION, I., SHAO, T., "Effects of elastic modulus mismatch between coating and substrate on the friction and wear properties of TiN and TiAlN coating systems", Wear, v. 338-339, n. Supplement C, pp. 54-61, 2015.

[45] COLOMBO, D. A., MANDRI, A. D., EChEVERRÍA, M. D., et al., "Mechanical and tribological 
behavior of Ti/TiN and TiAl/TiAlN coated austempered ductile iron", Thin Solid Films, v. 647, pp. 19-25, 2018.

\section{ORCID}

Diego Alejandro Colombo https://orcid.org/0000-0001-8439-4390

Adriana Beatriz Márquez https://orcid.org/0000-0002-8453-6261

Fernando García Marro https://orcid.org/0000-0003-3542-4332

Luis Miguel Llanes https://orcid.org/0000-0003-1054-1073

Amadeo Daniel Sosa https://orcid.org/0000-0002-3020-5723 